\title{
Identity, History, Tolerance
}

\author{
V.A. Surovtsev ${ }^{1 a}$, V.N. Syrov ${ }^{2}$ \\ ${ }^{1}$ Tomsk State University, 634050 Lenina str., 36, Tomsk, Russia \\ ${ }^{2}$ Tomsk State Pedagogical University, 634061 Kievskaja str., 60, Tomsk, Russia
}

\begin{abstract}
The article discusses the role of historical narratives in the formation of identity. Rüsen's thesis on the contradiction of traditional historical identities that suggest an ethnocentric position with the processes of intercultural communication is analyzed. The potential of historical narratives in overcoming (or restricting) ethnocentrism is considered. It is shown that ethnocentrism is constituted by kinds of the configuration of historical writing rather than by a subjective position of historical narrative authors. The types of stories suggest a) the way of making history using only the criteria of success and failure in the interpretation of the past; b) interpretation of history as teleological continuity; c) merely the necessity to justify (to substantiate claims) or to discredit something. It is alleged that the realization that the form of historical knowledge constructs, not discovers, can facilitate liberation from referential fallacy on the whole and enslavement by certain kinds of stories in particular. It is concluded that the recognition of the constitutive nature of historical narratives allows being independent from the traditional forms of historical knowledge and traditional ideas about their cultural value. In particular, it allows reconsidering the need to apply historical knowledge when constructing identity.
\end{abstract}

\section{Introduction}

Jörn Rüsen has repeatedly stated in his writings that historical narratives influence the orientation of practical life in time - an orientation without which it is impossible for humans to find their way [6]. He believes that this aim is achieved by solving three problems. A historical narrative "mobilizes the experience of the past", "organizes the internal unity of these three dimensions of time by means of a concept of continuity" and "serves to establish the identity of its authors and listeners" [6]. The thesis on the role of historical narratives in building identity looks obvious. Moreover, memory of the past seems to be a prerequisite and an integral part of identity formation.

In his latest works Rüsen notes that at least one of the functions of historical narratives is increasingly called into question. He notes that "this growing density in intercultural communication is a challenge of historical thinking", namely, "the globalization process confronts traditional historical identities with an accelerating change of life conditions, which highly problematizes the traditional distinction between the internal realm of the life of one's own people and the external realm of the lives of others" [7]. Rüsen believes that the reason for the growing confrontation is rooted in the traditional ways of building identity. "In situating themselves, subjects draw borderlines to others and their otherness within the locality and temporality of the common

\footnotetext{
a Corresponding author: surovtsev1964@mail.ru
}

world, in which they meet and differentiate from each other in order to be subjects themselves" [10]. This differentiation acquires a value-laden, namely asymmetrical character. In other words, "the positive evaluation of oneself logically leads to a negative view of the otherness of others" [7]. This way of building identity generates ethnocentrism; and Rüsen sees the root cause of this situation in the mechanism of identity formation rather than in the deliberately pursued ideology. The author stresses that "ethnocentrism (in all its different forms) is quasi-naturally inherent in human identity" [10].

The problem is that in modern conditions "a fundamental and universal clash of civilizations is constituted according to this logic of identity-formation" [7]; and this is happening both in life experience and at academic discourse levels. "Nobody can be neutral when one's own identity is in question" [7]. There is a conflict between identity preservation conditions and academic produce truth claims. Rüsen believes that "there is one way that establishes an equivalent of distance and of truth claims: the way of arguing" [7]. A reasonable question arises: what should a balance between distance and truth claims be? How is the way of arguing possible? Is the subjective integrity of professional historians sufficient for this?

\section{Materials and methods}


In this study we used the following methods: the comparative method, which allowed characterizing the basic features and specifics of modern ideas about the role of historical knowledge in the culture and the influence of cultural contexts on the kinds of configuration of historical writing; the hermeneutical method that helped to reveal implicit contexts of functioning of different outlooks on the form of historical writing and role of cultural determinants or cultural functions in the formation of dominant historical type-stories; the critical method, which allowed setting limits of using of such outlooks and their bases.

We used some ideas of Jörn Rüsen about the cultural role of historical narratives, in particular, their role in the formation of identity, and the impact of existing forms of historical knowledge on the occurrence of ethnocentrism. In the article we also used the Hayden White's views on the structure of historical knowledge and the role of cultural contexts in its formation. Hayden White elaborated the idea of emplotment as the main method to transform sources into historical knowledge.

\section{Results and discussion}

Ethnocentrism is a complex cultural orientation, and an integrated approach is required to overcome it. We only pay attention to the role of historical knowledge in the process. In the context of this approach, we argue, firstly, that ethnocentrism is constituted by kinds of configuration of historical writing rather than by the subjective position of authors of historical narratives. Therefore, the intention of researchers, they declare, does not guarantee overcoming the logic of ethnocentrism. Secondly, it is reasonable to argue that the dominance of certain kinds of stories is due to the dominant ideas on the role of historical knowledge in the culture. Thirdly, it is worthwhile to claim that the two topics are interrelated and mutually dependent. Then, the overcoming of ethnocentrism requires at least casting doubt both on the legitimacy of certain types of configuration of historical writing and on the justification of certain cultural functions of historical knowledge.

We shall start with the first point. Rüsen warns rightly against a simplistic approach to the problem. It is reasonable that the mere reversal of the oppositions "dominance / suppression", "center / periphery" does not reach its goals. "Most attempts to criticize Western ethnocentrism and to replace it by an enlightened image of non-Western cultures reproduce ethnocentrism by criticizing its Western manifestation" [11]. This is confirmed by a thesis on the constitutive role of forms of historical writing regardless of the intentions of its authors. We can argue that the same result will expect any other value system that researchers proclaim. Otherwise, any action will be similar to that of trying to pour new wine into an old skin. In other words, the existing forms of historical writing will simply block the possibility of implementing new value orientations.

What are the still dominant forms of historical writing? It is reasonable to assume that ethnocentric logic is not limited to a method for describing crosscultural interaction, yet it itself is a form of expression and an inevitable consequence of a more general way of perceiving the past. By analogy, this approach can be referred to as monocentric logic. What is it? Rüsen notes rightly that "teleological continuity is the dominant concept of time that rules the idea of history in master narratives" [7]. Therefore, "traditionally, historical development from the origins of one's own life-form through the changes of time to the present-day situation and its outlook into the future is a temporally extended version of all those elements of this special life-form, which constitute the mental togetherness of the people" [7]. Such history does not imply a distance or a gap between the past and the present. It is treated as a continuous process that links the past and the present by continuity. This means that we have to either take ourselves as followers of implementing the aims laid down by our predecessors, or see ancestors as our predecessors.

Another aspect of the monocentric logic is connected with the methods of the historical material delivery. In simple words, the dominant kinds of stories are constructed so that they can narrate successes or failures only. As Rüsen notes, "there is no way of making history without using criteria of success and failure, which always have a normative dimension" [9]. What matters here is not the narrative form that predetermines the distribution of the empirical material according to the following scheme: beginning-middle-end. The reason is in the kind of configuration that interprets some as losers and others as winners (at someone else's expense). These intentions of historical discourse can be both explicit and implicit in historical writing. But even if we are trying to write a problem-oriented story, the very nature of questions (explicated or implied by the text) "Who is the winner?" or "Who is the loser?" or the language of description (successes/failures) restricts the options of evidence interpretation as well as the space for evidence search. At best, the researcher is doomed to eclectics and use of the discourse employing such categories as "on the one hand" and "on the other hand".

Such an approach to creating stories programs and, at the same time, restricts the view on the past. It can only be the view of a winner or a loser; no other version is intended. This condemns the potential author of historical narratives to choose from only two alternatives. One can win or lose only at someone else's expense. This approach thus demonstrates the inability (not a mere lack of desire) to incorporate others' experience in own master narratives. The inability is caused by the predetermined format. Finally, as emphasized above, these kinds of stories will determine both the choice of the relevant evidence and the direction of search for this evidence. The problem is that the very process of writing these stories programs an ethnocentric point of view. As it has been rightly stated, "if historians limit their interests to what and who they can identify with and what is relevant for themselves, they are in danger of under-representing all kinds of minorities" [3].

Hayden White has aptly used the term emplotment to refer to a set of operations performed when writing 
stories. He noted, "by emplotment I mean simply the encodation of the facts contained in the chronicle as components of specific kinds of plot structures" [13]. White stressed that the form is not neutral with respect to the content. Thus, the types of configurations will determine the overall organization, distribution and selection of empirical material. White formulated this problem, when he wrote that "the question that arises with respect to 'historical emplotments' in a study of Nazism and the Final Solution is this: Are there any limits of the kind of a story that can responsibly be told about these phenomena? Can these events be responsibly emplotted in any of the modes, symbols, plot types, and genres of our cultures that provide for 'making sense' of extreme events in our past?" [14].

It is easy to notice that White's view is an expression of a theoretical position, an alternative to the one that "implies that the form in which historical events present themselves to a prospective narrator is found rather than constructed" [12]. Louis Mink described such a position as an opinion "that historical actuality itself has a narrative form and is an "untold story" [5]. "The historian's job is to discover that untold story, or part of it, and retell it even though in an abridged or edited form" $[5,188]$. As a rule, the result is that the kinds of stories themselves and the principles of their generation are identified with the essence of historical knowledge and even with the historical reality as such. Ultimately, such an approach turns into a belief that one can write a story only this way and not otherwise, because such writing corresponds to the order of things. A proponent of this approach "finds the story already hidden in what his data are evidence for; he is creative in the invention of research techniques to expose it, not in the art of narrative construction" [5]. As a result, failure to present other alternatives in a situation when the potential of the practiced forms of historical writing of stories is lost inevitably turns into a belief in the crisis of historical thinking.

Therefore, the task of constructivism supporters (or those gravitating towards it) is not just to show that we are dealing with texts rather than historical reality; it is more fundamental. It should show that history is created by such texts and exists only in them. Thus, the recognition of the constitutive function of kinds of configuration can facilitate liberation from referential fallacy on the whole and enchantment (even enslavement) by certain kinds of stories in particular. White was right to believe that the identification of kinds of configuration "would serve as a potential antidote to the tendency of historiography to became captive of ideological preconceptions" [13].

Consistent implementation of this approach requires a release from another fundamental prejudice. As White once noted, "the greatest historians have always dealt with those events in the histories of their cultures that are 'traumatic' in nature and the meaning of which is either problematical or overdetermined in the significance that they still have for current life" [13]. That is why they "refamiliarize with them, not only by providing more information about it, but also by showing how their developments conformed to one or another of the story types the we conventionally invoke to make sense of our own life-histories" [13]. This thesis about the relationship of cultural contexts (as cultural determinants or cultural functions) and historical knowledge has already become commonplace. But some aspects should be reiterated and even enhanced.

First of all, the cultural contexts are unavoidable. Moreover, it is only they that are able to make the generation of historical knowledge meaningful. It is more categorical to argue that both the interest in the past and various ways of interpreting it emerge only due to certain social and cultural needs. Figuratively speaking, the past as such becomes meaningful not out of its mere existence, but because it is necessary for solving certain practical (cultural) problems.

Secondly, it is reasonable to believe that the issue of the cultural (practical) value of historical knowledge or, in traditional terms, of the usefulness of history cannot be considered neutral to this knowledge itself. In other words, it is the use of history that shapes it. Then, the identification of cultural determinants or cultural functions of historical knowledge (both explicit and implicit) becomes important not only for better defining its cultural (practical) values, but also for understanding its internal structure. Following White, cultural contexts affect not only the content, but also the types of configuration of historical writing. White, as it is known, distinguished four kinds of plot structures and connected the use of such kinds of stories, in particular, with the fact that "historians shared with their audiences certain preconceptions [...], in response to imperatives that were generally extrahistorical, ideological, aesthetic, or mythical" [13].

Then, it can be assumed that over time the conditions for various forms of historical knowledge can also be forgotten. As a result, "we can confuse this, as we have, with reason, truth, rightness and the like, projected as embodied in specific practices" [2]. Therefore, it is necessary to agree with Rüsen that "self-understanding of historians as scholars lacks insight into the fundamental practical function of historical narration" [6]. He rightly emphasizes that "if professional historians recognized this function as a function of their own work, maybe their work would give a little bit more reasoning and arguing to practical life" [6].

However, in implementing such an approach one should also be free of at least two prejudices. The first is the belief that historical knowledge is first created and then used in practical life. It creates an illusion that a reasonable distance from practical needs will provide the required reliability of historical knowledge. Keith Jenkins rightly notes that academic historians operate "within acceptable limits and armed with all the usual gate-keeping paraphernalia: academic standards, publication controls, peer reviews, benchmarks, responsible and efficient methods" [4]. He continues: "That most academic historians do not think of things as due precisely to the silent and hidden mechanisms of ideological power in our current social formation" [4]. This approach gives rise to a belief that the subjective integrity of a historian is sufficient to ensure the reliability of knowledge. This approach also preserves 
the idea of the autonomy of the types of stories from the cultural tasks for which they were created. Such an autonomy does exist, but it shows in the fact that the existing forms of historical writing will simply block the possibility of implementing potential new value orientations.

On the other hand, one should get rid of the belief in the existence of permanent and unchanging cultural tasks which historical knowledge is designed to set. The same applies to the belief in the unchanging means by which these tasks are solved. With regard to the content of our stories, it is easy to see that they have emerged and still exist only out of the need to justify (to substantiate claims) or to discredit something. Therefore, story-types are designed to magnify or subvert certain participants in historical events and processes, be it individuals, institutions, states, or peoples. The idea that history is and should be not only the support, but also the justification of the legitimacy of our current claims is so deeply implanted in the culture that seems appropriate to the order of things. It seems paradoxical how historical knowledge can co-exist with such an ahistorical interpretation of its cultural role.

\section{Conclusion}

A clear understanding of the conditionality of content and forms of historical knowledge by the type of cultural needs allows coming to the following conclusions. Firstly, one does not have to constrain oneself by the prevailing format of cultural values or ways of implementing them. Rüsen demonstrates this in his criticism of the continuing forms of identity, namely, their ethnocentricity. He rightly calls for the implementation of "humankind as a constitutive factor of historical identity" [8]. Secondly, there is no need to be bound by traditional ideas about the aims and tasks of historical knowledge. It, first of all, concerns the role of history in the justification of identity. In other words, in the light of the idea of cultural determination of historical knowledge, one can assume that history is not a compulsory prerequisite and a component of constituting identity.

One can recognize and even insist on the narrative nature of identity. It is right to speak about its identical narrative and temporal structures. Yet, as David Carr noted in the light of Husserl's phenomenology, "retention and recollection are thus two radically different ways of being conscious of the past. Recollections come and go, whereas retention belong to all experience" [1]. Therefore, retention from recollection distinguishes "not the length of their term but their functioning as horizon for ongoing, present experience" [1]. This gives reason not to equate the historical past and the past considered as part of our identity. Skepticism about the role of history in the constitution of identity does not mean the loss of a need in historical knowledge. History can be dangerous for the building of identity, but essential for its normal functioning. Thus, in the implementation of our identity, we can face problems, the interpretation of which requires referring to the historical experience. But then we cannot constrain ourselves within the existing historical formats. In other words, we can assume that historical narratives cannot be reduced to story-types classified by Rüsen or White. The direction of the search for new types of configuration will depend on the ability of historical narratives to integrate the experience of others into their structure and ensure openness and sensitivity to the variety and diversity of direct or indirect voices in the evidence of the past.

\section{Acknowledgment}

This study was supported by the Tomsk State University Academician D.I. Mendeleev Fund Program in 2015. Professor Syrov would also like to thank the Russian Foundation for Humanities (grant No. 15-33-01003) for its support of this research.

\section{References}

1. J. Rüsen, History and Theory, 26 (4), 87-97 (1987)

2. J. Rüsen, History and Theory, 43 (4), 118-129 (2004)

3. J. Rüsen, The Journal for Transdisciplinary Research in Southern Africa, 3 (1), 169-221 (2007)

4. J. Rüsen, History and Theory, 51 (4), 45-59 (2012)

5. J. Rüsen, Criteria of Historical Judgment. In: Historical Truth, Historical Criticism and Ideology. Chinese Historiography and Historical Culture from a New Comparative Perspective, ed.by H.SchmidtGlintzer, A.Mittag and J.Rüsen, Brill, 133-141 (2005)

6. A. Froeyman, Rethinking History: The Journal of Theory and Practice, 16 (3), 393-415 (2013)

7. H. White, The Tropics of Discourse (Madison: The University of Wisconsin Press, 1987)

8. H. White, The History and Narrative Reader (G. Roberts, Routledge, 2001)

9. H. White, History and Theory, 23 (1), 1-33 (1984)

10. J. Rüsen, The Journal for Transdisciplinary Research in Southern Africa, 3 (1), 169-221 (2007)

11. L. O. Mink, Historical Understanding, edited by Brian Fay, Eugene O. Golob, and Richard T. Vann, Cornell University Press, 182-203 (1987)

12. S. Cohn, Rethinking History: The Journal of Theory and Practice, 17 (2), 155-171 (2013)

13. K. Jenkins, Refiguring History: new Thoughts on an old Discipline. Routledge (2003)

14. J. Rüsen, Journal of Interdisciplinary Studies in History and Archaeology, 1 (1), 10-21 (2004)

1. D. Carr, Time, Narrative, and History (Indiana Univ. Press, 1986) 